\title{
Environmental approaches to promote healthy eating: Is ensuring affordability and availability enough?
}

\author{
Pablo Monsivais and colleagues reflect on the evidence for interventions to improve access to \\ healthy food and discuss considerations for evidence generation
}

I mproving diet is a key goal of public health, as a substantial fraction of global morbidity and mortality is attributable to dietary imbalances. ${ }^{1}$ These imbalances include insufficient consumption of vegetables, fruits, and whole grains, and excessive intake of refined carbohydrates and meat. Moreover, inequities in health are driven in part by inequities in diet, and tackling them is a key dimension to improving diet and health at the population level.

The past 20 years have seen increasing concern over structural factors that promote unhealthy dietary patterns and undermine the adoption of healthy eating. This trend has paralleled a growing understanding of the multifactorial "causes of the causes" of the modern pandemics of obesity and non-communicable disease, ${ }^{2}$ and interest in the physical, economic, and social environments that cue and shape behavioural risk factors. ${ }^{34}$ For food selection and diet specifically, there is recognition of the importance of affordability and availability, two

\section{KEY MESSAGES}

- The evidence base linking food affordability and availability to healthy eating is equivocal, with affordability being more consistently identified as a key determinant but more controversial for policy

- Models of evidence generation remain reductionist and focused on local contexts; these need to embed greater attention to social determinants of health and the challenges faced by a globalised food system

- In times of unprecedented change and disruption, population health researchers must reflect on how evidence is generated and balance methodological rigour with the need for adaptive and pragmatic policy relevant research dimensions of a wider conceptualisation of food access (box 1). ${ }^{5}$ The general consideration of "access to healthy food" is now a central pillar of policy, systems, and environments (PSE) interventions ${ }^{7}$ as well as so called "whole systems" approaches ${ }^{8}$ to improve nutrition and reduce obesity and chronic disease. As policy makers and communities act to forge more healthful, sustainable, and equitable food systems and environments, researchers recognise the uneven evidence base and debate the importance of economic and geographical factors as population level determinants of diet and health.

What is the evidence to support policy action? Either implicitly or explicitly, considerations of affordability and availability are factored into some approaches to promote healthy diets. For example, government food assistance and other food subsidy programmes are predicated on improving affordability of healthy foods, while many policies aiming to create healthy community environments presume that availability is a determinant of food choice and dietary quality.

The scientific evidence informing population approaches to improve diet and health and reduce inequities arises from diverse observational, experimental, as well as natural or quasi-experimental studies. ${ }^{9}$ However, tensions exist between the needs of policy makers and researchers, stemming from the equivocal nature of the evidence base as well as the paucity of transferable theory of how interventions or policies work or why they fail.

\section{Affordability}

For more than 125 years, home economists and nutrition scientists have recognised the economic dimension of diets, including trade-offs between the nutritive value and cost of foods. ${ }^{10}$ Economic depression and food insecurity in the early 20th century focused attention on the affordability of nutritionally adequate diets. ${ }^{11}$ In the ensu- ing decades, evidence from economic, sociological, epidemiological, and consumer research has been largely convergent. Research on food prices, dietary costs, and affordability in relation to food choices and dietary quality has been based on highly varied data sources and study designs. Observational studies have examined food prices and affordability, variously defined as the cost of, or expenditure on, (healthier) food relative to income, in relation to diet and health. Generally, healthier foods and diets cost more for consumers, ${ }^{12}{ }^{13}$ and lower affordability, whether because of higher prices for healthier foods or lower incomes, is linked to the purchase or consumption of less healthy diets and poorer health outcomes. ${ }^{14}$ Although fewer studies have considered the time cost associated with healthier diets, ${ }^{15}$ research indicates that diets composed of minimally processed, healthy foods can be affordable in terms of ingredients but more costly when the time entailed in preparing meals is accounted for. ${ }^{1617}$

Interventions and programmes to tackle food affordability in low income populations have typically either subsidised incomes or made food available at reduced or no cost. ${ }^{18}$ Income subsidies are usually means tested, either subsidising food purchasing directly, such as the longstanding supplemental nutrition assistance programme (SNAP) in the United States, or through a general income transfer, such as Canada's universal child care benefit. Alternatively, the provision of food directly (rather than cash or vouchers), through food banks or pantries, has long been a critical resource for food insecure populations in the US and has grown substantially in the UK in the past decade. SNAP and more general income transfers have been shown to reduce food insecurity and improve diet among recipients. ${ }^{18}$ In contrast, food banks seem to be less effective at alleviating hunger and improving diet, although robust evaluations are limited. ${ }^{18}$ 
Box 1: Access, affordability, and availability

- Access: A broad construct seldom defined in diet and nutrition literature explicitly but analogous to its original formal definition in health services literature. It can be defined as "entry into or use of" food or food resources ${ }^{6}$

- Affordability: The monetary cost of food as well as perceptions of worth relative to the cost, often measured by store audits of specific foods or regional price indexes. Affordability implicitly or explicitly accounts for the money available for food, by considering food budgets, expenditures, or incomes ${ }^{4}$

- Availability: The adequacy of the supply of healthy food, typically measured at the community level or at the level of the retailing environment, or both. Community or neighbourhood level measures include measures of distance to healthier food outlets, as well as the presence or absence or density of outlets providing healthier options. At the retail environment level, availability can be quantified as the presence, quantity, and quality of healthier options ${ }^{4}$

More recently, policy makers have started to consider the manipulation of affordability through fiscal measures to promote healthier behaviours, including the selection of healthier foods. With the implementation of taxes on sugar sweetened beverages and other less healthy foods and beverages in dozens of countries so far, there is now substantial evidence that reducing affordability of these products can reduce their consumption at the population level, ${ }^{19}$ with largest reductions among lowest income households. A smaller evidence base indicates that subsidising healthier foods can promote healthier food choices. However, unlike taxation studies, in which taxes are levied by governments or local authorities, studies on subsidies have been largely investigator led and done in relatively small samples of low income and food insecure populations. ${ }^{20}$ Moreover, studies of subsidies have often combined the subsidy with an educational intervention or other intervention component. Comparatively little is known about the potential for subsidies to improve diets among the general population.

\section{Availability}

Food access research has typically defined availability at two scales: at the community scale in terms of the presence, density, and variety of supermarkets, grocery stores, or other retail outlets that sell healthier foods at relatively low prices; and, at the scale of the within store retail environment, describing the presence, quantity, and variety of healthy food options on the shelves. ${ }^{5}$ At either scale, observational studies suggest that limited availability is associated with poor diets, obesity, and higher risk of chronic disease, while other studies have not confirmed these associations. ${ }^{521}$ Weighing the mixed evidence, systematic reviews have called for more robust methods, preferably based on prospective designs and accounting for mobility patterns and potential selection effects, which haunt many observational studies of built environments and health.

More robust studies on availability within store retail environments have been based on investigator designed interventions. These enhance availability of healthier foods in convenience stores or other retail outlets that typically lack healthier options. Although these interventions could lead to beneficial changes in dietary and health outcomes, a limitation has been that they often combined the availability intervention with other intervention components (eg, educational materials or promotions), making it difficult to isolate the effects of individual components. ${ }^{22}$

Community scale studies have opportunistically examined the introduction of new healthy food retailing in communities where such options were previously lacking. Although some of these studies have methodological advantages compared with typical observational studies, ${ }^{5}$ such "natural experiments" have been hampered by other limitations, including relatively small sample size, limited follow-up time, and often limited measurement of dietary and health outcomes. Perhaps as a result, the balance of evidence based on these studies has been mixed, with most studies indicating little consistency between improved access and diet or health outcomes, which could result from methodological limitations. ${ }^{23}$

\section{What are the limitations of the evidence?}

Beyond the critiques around measurement and analysis, limitations arise in part because of the limited ways in which these concepts are operationalised for research, and in part because of the way that research evidence is generated in the field. As they stand, these concepts of affordability and availability do not fully capture the complexities and interactions of system level drivers; nor do they typically tackle the wider realities of societal inequity or consider the global food system and the threat of wider disruptions.

\section{Connecting to wider social inequalities}

Although subsidised food retail programmes show positive outcomes, their effectiveness is hampered by concerns of accountability, reach, uptake, cultural appropriateness, and equity. ${ }^{24}$ Such programmes essentially operate at the intersection of public health nutrition and welfare policy. ${ }^{25}$ One implication is that people interacting with these schemes often face marginalisation and stigma. ${ }^{26}$ Stigma can also inhibit the use of food banks and other food resources outside the retail sector by food insecure households. ${ }^{18}$ Failure to consider the social impact of accessing food banks and subsidised food retailing will render these food access interventions lacking in credibility, relevance, and acceptability.

Compared with affordability, availability is more flexibly interpreted in the literature. At a community scale, measures of availability typically converge on geographical distance to or density of specific classes of retail outlets. ${ }^{27}$ Access to donated, surplus, and waste food from food aid outlets, especially food banks, constitutes yet another form of availability, which is important in some settings, particularly for low income populations. ${ }^{28}$ Yet even with more nuanced accounting of the community food environment, a broader critique of this research and its motivating assumptions has been the reduction of the concept of availability to its geographical dimension, typical in the food deserts literature. ${ }^{2930}$

It's important to keep in mind that unhealthy diets and adverse health outcomes are symptomatic of wider social disadvantages and inequities. ${ }^{13} 31$ To date, food environment interventions have generally not considered the drivers of these inequalities. ${ }^{32}$ Yet without considering these upstream drivers, interventions that narrowly aim to improve affordability or availability, or both, may show only limited benefits, if any. One consequence is that costly and eagerly anticipated intervention studies often yield ambiguous results, without clear benefits to diet and health, disappointing both researchers and stakeholders. Worse, the 
failure of such structural interventions may reinforce individually focused narratives of poor diet and ill health, shifting blame on to marginalised groups.

Although practice and policy have made progress moving from individual level and high risk approaches to structural and population level approaches, the accounting for and redressing of fundamental causes of inequalities has lagged behind. So too has the recognition of the political economy of a globalised, commercial food system and its influence shaping local food availability and affordability. ${ }^{33}$

\section{Global food system and future disruptions}

Global events have implications for local food environments, including affordability and availability. ${ }^{34}$ For example, the great recession and the world food price crises in 2007-8 and 2010-12 had devastating impacts on the affordability and availability of food, with knock-on effects for population diet ${ }^{35}$ and even social unrest. ${ }^{36}$ Those worldwide disruptions were driven by factors well beyond the local food system, but their impact on diet and health was undeniable. The UN Food and Agriculture Organization monitors the affordability of healthy diets as a leading indicator of global food security, with the most recent update indicating that healthy diets are out of reach for large segments of the world's population. ${ }^{37}$

Most recently, the covid-19 pandemic has highlighted the interdependence of contemporary food supply chains, with considerable disruption in local retail food availability and pricing in several countries. ${ }^{38}$ The global crisis has moved some national governments to impose protectionist measures, including food export restrictions, with likely impacts on global food security. ${ }^{39}$ The pandemic has also highlighted the importance of fundamental causes of inequalities, as increasing numbers of households globally are being tipped into food insecurity by factors demonstrably beyond their control. Given high levels of global connectivity, it is likely that shocks to the food system, whether originating as pandemics or extreme climate events, will become progressively more common. ${ }^{40}$

Further, the large scale disruptions and perturbations that pose a threat to the stability and validity of investigator led interventions also present opportunities to better understand causal influences of key structural drivers of dietary behaviour. An increasing reliance on evaluative evidence ${ }^{9}$ must also recognise that individual and system level drivers of dietary behaviours are not independent, separate entities; these multiple levels interact and evolve dynamically over time to produce complex patterns of diet within and between countries across the globe. Our approach to research needs to be able to acknowledge and adapt to these global challenges. ${ }^{41}$

\section{Moving the evidence forward}

While there are gaps in the evidence, are we as researchers being piously but pointlessly empirical in the face of self-evident truths that affordability and availability matter for consumer food selection and diet? A rational rather than empirical approach might be enough to convince stakeholders about the need and nature of acting, but scientific evidence alone does not determine the appeal of intervention. Although price and affordability are strong determinants of food selection, the application of policies and interventions to tackle affordability through taxes or subsidies has been limited and controversial. By contrast, policies and interventions to promote availability have been more popular, with many policies and interventions moving forward despite thin evidence. ${ }^{27}$ Key remaining evidence gaps relate to whether and how policies, systems, and environments interact to facilitate healthy diets at the population level. This shifts the burden on researchers away from showing the "importance" of a potential determinant to investigating the impacts of policies and interventions squarely within their real world contexts, with the aim of generating more practicable evidence for action.

Evidence must emerge not only from classic researcher driven empirical studies that seek to approximate an experimental study approach, but should also be based on pragmatic evaluation of real world programmes and policies, recognising the need for ongoing policy learning. ${ }^{94} \mathrm{~A}$ detailed "evidence generation roadmap" for policy lacks a clear consensus; however, various principles of conducting quality research and responsible scholarship are likely to play a central part. These might entail the use of multidisciplinary teams applying a wider range of empirical methods and theory ${ }^{42}$; the need to invest in the development of combined individual and system level data infrastructure to support rapid analysis and evidence synthesis ${ }^{43}$; challenging the primacy of randomised controlled trials and traditional evidence hierarchies ${ }^{44}$; embracing a model of engaged scholarship ${ }^{45}$; and responsive, flexible funding mechanisms that allow access to rapid funding and adaptation in scientific direction when necessary. ${ }^{43}$ Dietary public health research needs to adapt and evolve urgently, given globalisation and the requirement to be prepared for large scale disruptions.

Understanding the importance of food access in promoting healthy diets will require multiple disciplinary perspectives and approaches. The judicious selection of methods and research designs that acknowledge the complexity of food systems will be essential for generating evidence on the affordability and availability of food in shaping food choice, diet quality, and health.

Contributors and sources: PM is a public health researcher focused on dietary and health inequities and social determinants of health. CT is a qualitative researcher with interests in food poverty, urban inequalities, welfare reform, regeneration, and food and alcohol environments. CCA is a postdoctoral researcher in global health with interests in supporting the development of a healthier, fairer, and more sustainable food system both nationally and globally. TLP's research focuses on improving food availability, healthy sustainable food system transition, and the effect of national policies on population and planetary health. PM is the guarantor of this article.

Competing interests: We have read and understood BMJ policy on declaration of interests and have no conflicts of interest to declare.

PM received support from the Health Equity Research Center, a strategic research initiative of Washington State University. CT is supported by the NIHR Applied Research Collaboration East of England. The views expressed are those of the authors and not necessarily those of the NHS, the NIHR, or the Department of Health and Social Care.

Provenance and peer review: Commissioned; externally peer reviewed.

This article is part of series commissioned by The $B M J$. Open access fees are paid by Swiss Re, which had no input into the commissioning or peer review of the articles. The BM/ thanks the series advisers Nita Forouhi, Dariush Mozaffarian, and Anna Lartey for valuable advice and guiding selection of topics in the series.

Pablo Monsivais, associate professor

Claire Thompson, senior research fellow ${ }^{2}$

Chloe Clifford Astbury, researcher ${ }^{3}$

Tarra L Penney, assistant professor ${ }^{3}$

${ }^{1}$ Elson S Floyd College of Medicine, Washington State University, Spokane, USA

${ }^{2}$ School of Health and Social Work, University of Hertfordshire, Hatfield, UK

${ }^{3}$ School of Global Health, Global Strategy Lab, Faculty of Health, York University, Toronto, Ontario, Canada

Correspondence to: Pablo Monsivais

p.monsivais@wsu.edu

\section{Check for updates}

This is an Open Access article distributed in accordance with the Creative Commons Attribution Non Commercial (CC BY-NC 4.0) license, which 
permits others to distribute, remix, adapt, build upon this work non-commercially, and license their derivative works on different terms, provided the original work is properly cited and the use is non-commercial. See: http://creativecommons.org/ licenses/by-nc/4.0/.

\section{@@ OPEN ACCESS}

1 Afshin A, Sur PJ, Fay KA, et al, GBD 2017 Diet Collaborators. Health effects of dietary risks in 195 countries, 1990-2017: a systematic analysis for the Global Burden of Disease Study 2017. Lancet 2019;393:1958-72. doi:10.1016/S01406736(19)30041-8

2 Rose GA, Khaw K-T, Marmot M. Rose's strategy of preventive medicine: the complete original text. Oxford University Press, 2008. doi:10.1093/acp rof:oso/9780192630971.001.0001

3 Butland B, Jebb S, Kopelman P, et al. Foresight tackling obesities: future choices-project report. Government Office for Science, 2007:1-161. https:// www.gov.uk/government/uploads/system/uploads/ attachment_data/file/287937/07-1184x-tacklingobesities-future-choices-report.pdf

4 CDC. The four domains of chronic disease prevention. CDC, 2015

5 Caspi CE, Sorensen G, Subramanian SV, Kawachi I. The local food environment and diet: a systematic review. Health Place 2012;18:1172-87. doi:10.1016/j.healthplace.2012.05.006

6 Penchansky R, Thomas JW. The concept of access: definition and relationship to consumer satisfaction. Med Care 1981;19:127-40. doi:10.1097/00005650-198102000-00001

7 Lyn R, Aytur S, Davis TA, et al. Policy, systems, and environmental approaches for obesity prevention: A framework to inform local and state action. J Public Heal Manag Pract 2013;19:S23-33.

8 Bagnall AM, Radley D, Jones R, et al. Whole systems approaches to obesity and other complex public health challenges: a systematic review. BMC Public Health 2019;19:8. doi:10.1186/s12889-0186274-z

9 Ogilvie D, Adams J, Bauman A, et al. Using natural experimental studies to guide public health action: turning the evidence-based medicine paradigm on its head. J Epidemiol Community Health 2020;74:2038. doi:10.1136/jech-2019-213085

10 Atwater WO. Foods: nutritive value and cost. US Department of Agriculture, 1894.

11 Orr JB. Food health and income: Report on a survey of adequacy of diet in relation to income. Macmillan, 1937.

12 Rao M, Afshin A, Singh G, Mozaffarian D. Do healthier foods and diet patterns cost more than less healthy options? A systematic review and meta-analysis. BMJ Open 2013;3:e004277. doi:10.1136/ bmjopen-2013-004277

13 Food Foundation. The broken plate. 2019 https://foodfoundation.org.uk/wp-content/ uploads/2019/02/The-Broken-Plate.pdf

14 Powell LM, Chriqui JF, Khan T, Wada R, Chaloupka FJ. Assessing the potential effectiveness of food and beverage taxes and subsidies for improving public health: a systematic review of prices, demand and body weight outcomes. Obes Rev 2013;14:110-28. doi:10.1111/obr.12002
15 Monsivais P, Aggarwal A, Drewnowski A. Time spent on home food preparation and indicators of healthy eating. Am J Prev Med 2014;47:796-802. doi:10.1016/jamepre.2014.07.033

16 Davis GC, You W. The Thrifty Food Plan is not thrifty when labor cost is considered. J Nutr 2010;140:854 7. doi:10.3945/jn.109.119594

17 Tharrey M, Drogué S, Privet L, Perignon M, Dubois C, Darmon N. Industrially processed $v$ homeprepared dishes: what economic benefit for the consumer?Public Health Nutr 2020;23:1982-90. doi:10.1017/S1368980019005081

18 Loopstra R. Interventions to address household food insecurity in high-income countries. Proc Nutr Soc 2018;77:270-81. doi:10.1017/ S002966511800006X

19 Teng AM, Jones AC, Mizdrak A, Signal L, Genç M, Wilson N. Impact of sugar-sweetened beverage taxes on purchases and dietary intake: systematic review and meta-analysis. Obes Rev 2019;20:1187-204. doi:10.1111/obr.12868

20 Afshin A, Peñalvo JL, Del Gobbo L, et al. The prospective impact of food pricing on improving dietary consumption: a systematic review and meta-analysis. PLoS One 2017;12:e0172277. doi:10.1371/journal.pone.0172277

21 Cobb LK, Appel LJ, Franco M, Jones-Smith JC, Nur A, Anderson CA. The relationship of the local food environment with obesity: a systematic review of methods, study quality, and results. Obesity (Silver Spring) 2015;23:1331-44. doi:10.1002/oby.21118

22 Gittelsohn J, Trude A. Diabetes and obesity prevention: changing the food environment in low income settings. Nutr Rev 2017;75(suppl 1):62-9. doi:10.1093/nutrit/nuw038

23 Abeykoon AH, Engler-Stringer R, Muhajarine $N$. Health-related outcomes of new grocery store interventions: a systematic review. Public Health Nutr 2017;20:2236-48. doi:10.1017/ S1368980017000933

24 Galloway T. Canada's northern food subsidy nutrition north Canada: A comprehensive program. Stand Alone Books, 2018. doi:10.1596/978-1-46481087-9

25 Alderman H, Gentilini U, Yemtsov R.The 1.5 billion people question: food, vouchers, or cash transfers? Stand Alone Books,2018. doi:10.1596/978-1-4648-1087-9

26 Wiseman M. The Supplemental Nutrition Assistance Program. In: O'Leary CJ, Stevens D, Wandner SA, Wiseman M, eds. Strengths of the social safety net in the great recession. Upjohn Institute, 2019 doi:10.17848/9780880996648.Ch3

27 Cummins S, Macintyre S. "Food deserts"evidence and assumption in health policy making. BMJ 2002;325:436-8. doi:10.1136/ bmj.325.7361.436

28 Thompson C, Smith D, Cummins S. Food banking and emergency food aid: expanding the definition of local food environments and systems. Int J Behav Nutr Phys Act 2019;16:2. doi:10.1186/s12966-018 0765-2

29 Block JP, Subramanian SV. Moving beyond "food deserts": reorienting United States policies to reduce disparities in diet quality. PLOS Med 2015;12:e1001914. doi:10.1371/journal. pmed.1001914

30 Widener M). Spatial access to food: Retiring the food desert metaphor. Physiol Behav 2018;193(Pt B):257-60. doi:10.1016/j.physbeh.2018.02.032
31 Marmot M. Health equity in England: the Marmot review 10 years on. BMJ 2020;368:m693. doi:10.1136/bmj.m693

32 Agyeman J, McEntee J. Moving the field of food justice forward through the lens of urban political ecology. Geogr Compass 2014:8:211-20. doi:10.1111/ gec3.12122

33 White M, Aguirre E, Finegood DT, Holmes C, Sacks $\mathrm{G}$, Smith R. What role should the commercial food system play in promoting health through better diet?BMJ 2020;368:m545. doi:10.1136/bmj.m545

34 Pescud M. Friel S, Lee A, et al. Extending the paradigm: a policy framework for healthy and equitable eating (HE2). Public Health 2018;21:347781. doi:10.1017/S1368980018002082

35 Brinkman H-J, de Pee S, Sanogo I, Subran L, Bloem MW. High food prices and the global financial crisis have reduced access to nutritious food and worsened nutritional status and health. | Nutr 2010;140:153S-61S. doi:10.3945/ jn.109.110767

36 Koren O, Winecoff WK. Food price spikes and social unrest: The dark side of the fed's crisis-fighting. Foreign Policy 2020 May 20. https://foreignpolicy. com/2020/05/20/food-price-spikes-and-socialunrest-the-dark-side-of-the-feds-crisis-fighting/

37 FAO, IFAD, UNICEF, WFP, WHO. The state of food security and nutrition in the world 2020 : Transforming food systems for affordable healthy diets. UNICEF, 2020

38 Covid-19 food price monitor. Food Security Portal, 2020

39 Reardon T, Bellemare MF, Zilberman D. How COVID-19 may disrupt food supply chains in developing countries. In: Covid-19 and Global Food Security. International Food Policy Research Institute, 2020:78-80. https://www.ifpri.org/publication/ how-covid-19-may-disrupt-food-supply-chainsdeveloping-countries

40 Berry EM, Dernini S, Burlingame B, Meybeck A, Conforti P. Food security and sustainability: can one exist without the other?Public Health Nutr 2015;18:2293-302. doi:10.1017/ S136898001500021X

41 Dunlop CA, Radaelli CM. Systematising policy learning: from monolith to dimensions. Polit Stud 2013;61:599-619. doi:10.1111/j.14679248.2012.00982.x

42 Hawe P, Potvin L. What is population health intervention research?Can J Public Health 2009;100:18-14. doi:10.1007/ BF03405503

43 Rutter H, Savona N, Glonti K, et al. The need for a complex systems model of evidence for public health. Lancet 2017;390:2602-4. doi:10.1016 S0140-6736(17)31267-9

44 Moore GF, Evans RE, Hawkins J, et al. From complex social interventions to interventions in complex social systems: Future directions and unresolved questions for intervention development and evaluation. Evaluation (Lond) 2019;25:23-45. doi:10.1177/1356389018803219

45 Bowen SI, Graham ID. From knowledge translation to engaged scholarship: promoting research relevance and utilization. Arch Phys Med Rehabil 2013:94(suppl):S3-8. doi:10.1016/j. apmr.2012.04.037

Cite this as: $B M / 2021 \cdot 372 \cdot n 549$

http://dx.doi.org/10.1136/bmj.n549 